\title{
Seroprevalence of Helicobacter pylori infection and its related risk factors in symptomatic patients in southern Ethiopia
}

\author{
Endale Tadesse*, Deresse Daka, Demo Yemane and Techalew Shimelis
}

\begin{abstract}
Background: Helicobacter pylori is the main etiology of peptic ulcers and chronic gastritis. Various studies showed that blood type ' $\mathrm{O}$ ' is more common among patients with peptic ulcer. The aim of this study was to determine the seroprevalence of $\mathrm{H}$. pylori antibodies and its relationship with $\mathrm{ABO} /$ Rhesus blood groups, age, sex and residence of symptomatic patients in southern Ethiopia.

Methods: A cross-sectional study was conducted in a total of 408 consecutive patients with upper abdominal complaints at Hawassa University Hospital from October 2012 to January 2013. Data on demographic factors was collected from all participants using questionnaires. Blood samples were also collected and tested for ABO and Rh blood group phenotype using hemagglutination test and for anti-H. pylori antibody (lgG) using two different ELISAs.

Results: The overall seroprevalence of $H$. pylori infection was $83.3 \%$ (340/408), and it was significantly higher in rural (71.2\%) compared to urban residents (28.8\%) $(p=0.008)$. Participants with blood group $A B, A, O, B$, and Rh positive had $H$. pylori prevalence of $88.9,84.2,83.7,80.9$, and $83.5 \%$, respectively. $H$. pylori infection was not significantly influenced by age, sex, occupation, educational status and $A B O /$ Rh status $(p>0.05)$.

Conclusion: The high seroprevalence of $H$. pylori infection especially among rural residents calls for immediate intervention measures so that its clinical consequences could be minimized. ABO/Rh blood group was not found to be associated with $H$. pylori infection.
\end{abstract}

Keywords: Helicobacter pylori, ABO blood groups, Seroprevalence

\section{Background}

Helicobacter pylori is a small, spiral-shape, Gram-negative bacillus that inhabit the mucous layer overlying the gastric epithelial cells in humans [1]. The organism has been etiologically associated with chronic active gastritis [2], peptic ulcer disease [3], gastric cancer [4] and mucosal associated lymphoid tissue (MALT) lymphoma [5]. It is estimated that up to $50 \%$ of the world population are infected with H. pylori [6]. Prevalence is higher in developing countries than developed nations [7], and varying within and among countries [8]. In Ethiopia, studies have showed the high prevalence of $H$. pylori infection among adults in various localities $[9,10]$, similar to results from other developing

\footnotetext{
* Correspondence: endaletd@yahoo.com

Department of Medical Laboratory Science, College of Medicine and Health Sciences, Hawassa University, P.O. Box 1560, Hawassa, Ethiopia
}

countries $[11,12]$. As $H$. pylori is largely transmitted by the fecal-oral route, poor hygiene practice, overcrowding and lack of sanitation are important factors for its preponderance in developing countries [8]. An experience of developed nations showed that improvement of hygiene condition significantly decreased the prevalence of the infection [13].

Despite high prevalence of $H$. pylori infection, most infected people remain asymptomatic and only minorities develop peptic ulcer disease [11]. It may be the host genetic factors and/or $H$. pylori strains that determine the clinical significance of the infection. Boren et al. reported that individuals with blood group $\mathrm{O}$ and with Lewis b antigen more likely develop gastritis, since these antigens mediate the attachment of $H$. pylori to the gastric mucosa [14]. It was also shown that the frequency of 
$\mathrm{O}$ blood group and non-secretor phenotype of $\mathrm{ABO}$ antigens are higher among patients with peptic ulcers [15-19]. However, several studies reported absence of association between $H$. pylori infection and ABO blood groups [20-22].

In developing nations, the required health finance to properly manage $H$. pylori infection, which results in diseases including peptic ulcer and gastric cancer, is unaffordable [11]. Thus, planning prevention measures that reduce the public health significance of $H$. pylori infection is critically needed. In this regard, investigating the epidemiology of the infection in various localities is required to design effective intervention measures. Therefore, this study aimed at assessing the seroprevalence of $H$. pylori infection and its related risk factors in southern Ethiopia.

\section{Methods}

\section{Study area and design}

A cross-sectional study was conducted at Hawassa Teaching and Referral Hospital, in southern Ethiopia, from October 2012 to January 2013. The hospital is situated in Hawassa, the capital city of the Southern Nations, Nationalities and People's Regional state in Ethiopia, and the largest public hospital in the administrative region. Patients with clinical indications for $H$. pylori infection are routinely tested in the hospital using rapid serological diagnostic tests.

\section{Study population and sample size}

The study population consisted of patients examined at the outpatient department of the Hospital and with clinical indications of $H$. pylori infection. Participants less than 15 years of age and who took treatment against H. pylori infection a month prior to this study were excluded. In total, 408 consecutive patients were included in the study.

\section{Data collection}

A trained nurse collected data on socio-demographic factors such as age, sex, residence, occupation, and educational level using questionnaires. About $5 \mathrm{ml}$ of venous blood were collected from the participants for blood grouping and serology. Blood samples were allowed to clot and centrifuged at 3000 RPM for 10 minutes; sera were separated and refrigerated at $-20^{\circ} \mathrm{C}$ until tested.

\section{Blood grouping}

$\mathrm{ABO} / \mathrm{Rh}$ blood grouping was performed using direct tube hemagglutination method.

\section{Serology}

Sera were tested for anti-H. pylori immunoglobulin G (IgG) using two different enzyme linked immunosorbent assay (ELISA) kits: Pyloriset EIA-G III (Orion Diagnostica, Germany) and $H$. pylori IgG ELISA (IBL International, Hamburg, Germany). The procedure for the ELISAs was described elsewhere [23], and concordant results determined $H$. pylori infection status of the participants.

\section{Data analysis}

Data entry and analysis was performed using SPSS Version-16. Results were summarized using descriptive statistics. Pearson's Chi-square $\left(X^{2}\right)$ test was used to evaluate differences between proportions and $\mathrm{p}$-value less than 0.05 was considered statistically significant.

\section{Ethical consideration}

The study was approved by the Institutional Review Board of College of Medicine and Health Sciences, Hawassa University. Participation was fully voluntary and informed consent was obtained from each study participant. Screening for $H$. pylori infection was performed free of charge, and those found positive was managed by physicians.

\section{Results}

\section{Study participants}

Out of 419 patients approached during the study period, $11(2.6 \%)$ were excluded because of 3 patients were on anti-H. pylori treatment, 1 refused to participate, 4 had discordant ELISA results and 3 were children under 15 years old. Thus, data from 408 patients was considered for analysis. Participants had mean age of 35 years (range; 15 - 96 years) and the male to female ratio was 1.04:1. The mean age of the study subjects was 35 years (range, 15 - 96 years), and majorities, 305 (74.8\%), were below the age of 45 years. The majority of the participants (73.6\%) were rural residents and farmers $(20.6 \%)$ by occupation. Blood group $\mathrm{O}$ was the most frequent $(40.7 \%)$ phenotype followed by type A (27.9\%), type B (27.0\%), and type $\mathrm{AB}(4.4 \%)$. The vast majority of the participants were $\mathrm{Rh}$ positive (96.8\%).

\section{H. pylori infection and its distribution by socio-demographic factors}

The overall prevalence of $H$. pylori infection was found to be $83.3 \%$ (340/408) by double ELISA testing. The distribution of infection by socio demographic factors is presented in Table 1. The infection occurred more frequently among male participants (51.8\%) compared to females (48.2\%) though the difference was not statistically significant $(\mathrm{p}=0.508)$. As shown in Figure 1 , exposure to H. pylori seems to be higher among participants in the age group 25 - 34 years (88\%) though age was not found to be associated with infection status $(p=0.479)$. However, the infection occurred in significantly higher rate 
Table 1 Socio-demographic characteristics and seropositivity of $H$. pylori infection in southern Ethiopia, 2012-2013

\begin{tabular}{|c|c|c|c|c|c|}
\hline Characteristics & Total tested No (\%) & $\begin{array}{l}\text { Seropositive } N=340 \\
\text { No }(\%)\end{array}$ & $\begin{array}{l}\text { Seronegative } \mathrm{N}=68 \\
\text { No }(\%)\end{array}$ & $X^{2}$-value & $p$-value \\
\hline $\operatorname{Sex}(M / F)$ & & & & 0.502 & 0.508 \\
\hline M & $208(51)$ & $176(51.8)$ & $32(47.1)$ & & \\
\hline $\mathrm{F}$ & $200(49)$ & $164(48.2)$ & $36(52.9)$ & & \\
\hline Occupation & & & & 4.396 & 0.820 \\
\hline Farmer & $84(20.6)$ & $71(84.5)$ & $13(15.5)$ & & \\
\hline House wife & 79 (19.4) & $64(81)$ & $15(19)$ & & \\
\hline Gov't employee & $70(17.2)$ & $58(82.9)$ & $12(17.1)$ & & \\
\hline NGO Employee & $58(14.2)$ & $46(79.3)$ & $12(20.7)$ & & \\
\hline Student & $71(17.3)$ & $66(93)$ & $5(7)$ & & \\
\hline Merchant & $26(6.4)$ & $21(80.8)$ & $5(19.2)$ & & \\
\hline Un employee & $20(4.9)$ & $14(70)$ & $6(30)$ & & \\
\hline Residency & & & & 7.117 & 0.008 \\
\hline Rural & $301(73.8)$ & $242(71.2)$ & $59(86.8)$ & & \\
\hline Urban & $107(26.2)$ & $98(28.8)$ & $9(13.2)$ & & \\
\hline Educational statues & & & & 0.882 & 0.348 \\
\hline Illiterate & $136(33.3)$ & $110(80.9)$ & $26(19.1)$ & & \\
\hline literate & $272(66.7)$ & $230(84.6)$ & $42(13.4)$ & & \\
\hline Total & $408(100)$ & 340 (83.3) & $68(16.7)$ & & \\
\hline
\end{tabular}

among residents in rural compared to urban sites $(71.2$ versus $28.8 \%$; $\mathrm{p}=0.008$ ).

The distribution of $H$. pylori infection among participants with different blood types indicated that those with blood type $\mathrm{AB}, \mathrm{A}, \mathrm{O}$, and $\mathrm{B}$ had 88.9, 84.2, 83.7 and $80.9 \%$ rate of infection, respectively (Table 2 ). $\mathrm{RH}$ positive individuals had higher rate of exposure to $H$. pylori compared to $\mathrm{RH}$ negatives (83.5\% versus $76.9 \%)$. However, neither $\mathrm{ABO}$ blood type $(\mathrm{p}=0.814)$ nor $\mathrm{RH}$ status $(\mathrm{p}=$ $0.535)$ significantly influenced $H$. pylori infection.

\section{Discussion}

Overall, the seroprevalence of $H$. pylori infection among symptomatic patients attending the outpatient department of Hawassa Teaching and Referral Hospital was 83.3\%, which is in agreement with results reported from Ethiopia; 85.6\% in Gondar [10] and $69-91 \%$ in Addis Ababa $[9,24]$. In contrast, our finding was higher than other results reported from Ethiopia; 49 - 70\% in Bahirdar [20], $56-70 \%)$ in Addis Ababa [25,26] and 66\% in Gondar [27]. Also, the present result was found to be lower than

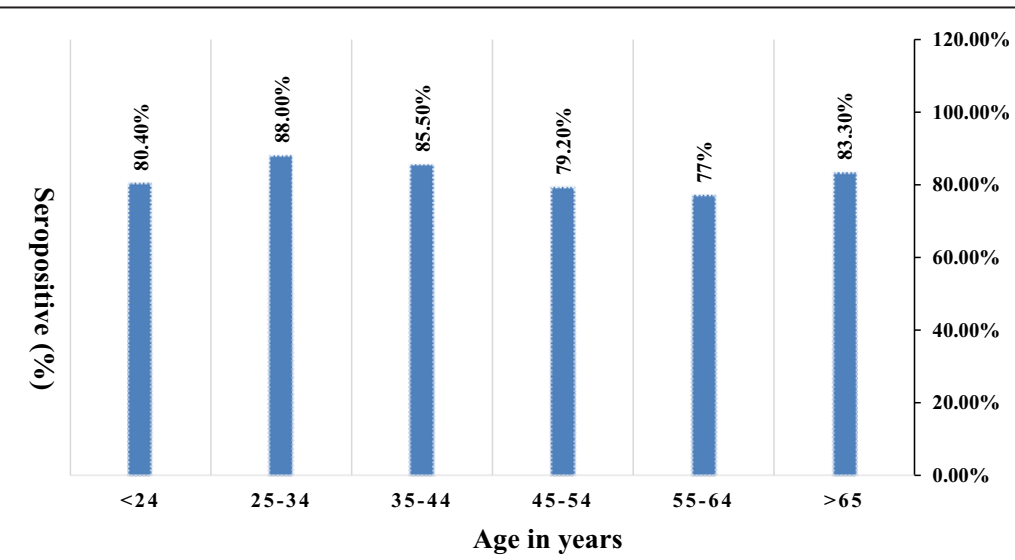

Figure 1 Seropositivity of - infection among different age group in southern Ethiopia, 2012-2013. 
Table 2 Association of ABO/Rh blood group and $H$. pylori infection in southern Ethiopia, 2012-2013

\begin{tabular}{|c|c|c|c|c|c|}
\hline \multirow[t]{2}{*}{ Blood group } & \multirow{2}{*}{$\begin{array}{l}\text { Total tested } \\
\text { No }(\%)\end{array}$} & \multirow{2}{*}{$\begin{array}{l}\text { Seropositive }(n=340) \\
\text { No }(\%)\end{array}$} & Seronegative $(n=68)$ & \multirow[t]{2}{*}{$X^{2}$-value } & \multirow[t]{2}{*}{$p$-value } \\
\hline & & & No (\%) & & \\
\hline ABO blood group $(n=408)$ & & & & 0.948 & 0.814 \\
\hline $\mathrm{O}$ & $166(40.7)$ & $139(83.7)$ & $27(16.3)$ & & \\
\hline A & $114(27.9)$ & $96(84.2)$ & $18(13.8)$ & & \\
\hline B & $110(27)$ & $89(80.9)$ & $21(19.1)$ & & \\
\hline$A B$ & $18(4.4)$ & $16(88.9)$ & $2(11.1)$ & & \\
\hline Rh blood group $(n=408)$ & & & & 0.386 & 0.535 \\
\hline Rh negative & $395(96.8)$ & $10(76.9)$ & $3(23.1)$ & & \\
\hline Rh positive & $13(3.2)$ & $330(83.5)$ & $65(16.5 .6)$ & & \\
\hline
\end{tabular}

the figures reported in Iran (46.6 - 64.8\%) [18,28,29], Turkey (68\%) [21], and in Portugal City of Coimbra (67\%) [19]. The higher prevalence of $H$. pylori infection may be related to poor personal hygiene, low standard of living and low economic status among dyspeptic patients in the study area.

Although the significance of age to influence $H$. pylori infection was shown elsewhere $[7,10,21,17,27]$, this contrasts our and others' findings [20,26,28]. Moreover, the role of sex to differentially put men at higher risk of infection compered to women was also shown by others $[17,30,31]$ though this could not be revealed in the current and similar previous studies [9,20,21,27,28]. Our finding, which indicated the higher prevalence of $H$. pylori infection in rural residents compared to urban, was in line with a report elsewhere [21], and it may be attributed to factors related to the lack of safe water supply and hygiene condition in the rural part of the country.

As to the relation between $\mathrm{ABO}$ blood group and $H$. pylori infection, contrasting evidences exists in which some studies revealed the presence of association [17-19], while others not [2,20-22,24,29]. Similar to the latter groups, we observed neither $\mathrm{ABO}$ nor Rh was significantly associated with infection in our study population, which challenges reports indicating participants with blood type $\mathrm{O}$ are more prone to $H$. pylori infection.

$H$. pylori infection was detected using serological test, which is acceptable for epidemiological studies. However, serological tests unable to differentiate current infection from previous infections. Thus, in order to reveal whether the finding reported in this study reflects the actual situation of $H$. pylori infection in the general population, further community based studies should be conducted using different diagnostic methods such as culture, histological test, urease test, serology and gram staining.

\section{Conclusions}

In conclusion, the seroprevalence of $H$. pylori infection was high among symptomatic patients at Hawassa
University Hospital. Though the infection status was significantly affected by residence site, no association was observed with age, sex, occupation, educational status and $\mathrm{ABO} / \mathrm{Rh}$ blood type. The burden of $H$. pylori that we reported warrants the need to design and implement intervention measures that could reduce transmission, and thus lessen the clinical consequences of infection.

\section{Competing interests}

The authors declare that they have no competing interests.

\section{Authors' contributions}

ET was the principal investigator for the study; ET, DY, DD and TS contributed to the design of the study; ET and TS supervised data collection; DD and DY performed the statistical analyses; ET and TS interpreted the result; all authors contributed to the write up and approved the final manuscript.

\section{Acknowledgements}

The authors would like to thank to the Hawassa University for financial support of the study. We extend our appreciation to Ms. Yeshiaharg Behailu for technical assistance during laboratory work and finally to the study subjects who voluntarily participated in this study.

Received: 12 June 2014 Accepted: 18 November 2014

Published: 24 November 2014

\section{References}

1. Hernandez F, Rivera P, Sigaran MF, Aguilar-Ortiz M, Miranda J, RodríguezJenkins O, Murillo M: The first cases of Helicobacter pylori (Campylobacter pylori) reported from Costa Rica. Rev Biol Trop 1990, 38:481-482.

2. Loffeld RJ, Stobberingh E: Helicobacter pylori and $A B O$ blood groups. J Clin Pathol 1991, 44(6):516-517.

3. Dixon MF: Helicobacter pylori and peptic ulceration: histopathological aspects. J Gastroenterol Hepatol 1991, 6:125-130.

4. Uemura N, Okamoto S, Yamamoto S, Matsumura N, Yamaguchi S, Yamakido M, Taniyama K, Sasaki N, Schlemper RJ: Helicobacter pylori infection and the development of gastric cancer. N Engl J Med 2001, 345:784-789.

5. Parsonnet J, Hansen S, Rodriguez L, Gelb BA, Warnke AR, Jellum E, Orentreich N, Vogelman HJ, Friedman DG: Helicobacter pylori infection and gastric lymphoma. N Engl J Med 1994, 330(18):1267-1271.

6. Goodwin CS, Mendall MM, Northfield TC: Helicobacter pylori infection. Lancet 1997, 349:265-269.

7. Graham DY, Adam E, Reddy GT, Agarwal JP, Agarwal R, Evans DJ Jr, Malaty HM, Evans DG: Seroepidemiology of Helicobacter pylori infection in India: comparison of developing and developed countries. Dig Dis Sci 1991, 36:1084-1088.

8. Hunt RH, Xiao SD, Megraud F, Leon-Barua R, Bazzoli F, van der Merwe S, Vaz Coelho LG, Fock M, Fedail S, Cohen H, Malfertheiner P, Vakil N, Hamid S, Goh KL, Wong BC, Krabshuis J, Le Mair A: Helicobacter pylori in developing 
countries: world gastroenterology organisation global guideline. J Gastrointestin Liver Dis 2011, 20:299-304.

9. Asrat D, Nilsson I, Mengistu Y, Ashenafi S, Ayenew K, Abu Al-Soud W, Wadstrom T, Kassa E: Prevalence of Helicobacter pylori infection among adult dyspeptic patients in Ethiopia. Ann Trop Med Parasitol 2004, 98:181-189.

10. Feleke M, Afework K, Getahun M: Seroprevalence of Helicobacter pylori in dyspeptic patients and its relationship with HIV infection, ABO blood groupings and life style in University Hospital, northwest Ethiopia. World J Gastroenol 2006, 12:1957-1961.

11. Salih BA: Helicobacter pylori infection in developing countries: the burden for how long? Saudi J Gastroenterol 2009, 15(3):201-207.

12. Bardhan PK: Epidemiological features of Helicobacter pylori infection in developing countries. Clin Infect Dis 1997, 25:973-978.

13. Elitsur Y, Dementieva Y, Rewalt M, Lawrence Z: Helicobacter pylori infection rate decreases in symptomatic children: a retrospective analysis of 13 years (1993-2005) from a gastroenterology clinic in West Virginia. J Clin Gastroenterol 2009, 43:147-151.

14. Boren T, Falk P, Roth KA, Larson G, Normark S: Attachment of Helicobacter pylori to human gastric epithelium mediated by blood group antigens. Science 1993, 262:1892-1895.

15. Aird I, Bentall HH, Roberts JAF: A relationship between cancer of stomach and the ABO blood groups. BMJ 1953, 1:799-801.

16. Clarke CA, Edwards JW, Haddock DRW, Howel-Evans AW, McConnell RB, Sheppard PM: ABO blood groups and secretor character in duodenal ulcer. BMJ 1956, 2:725-731.

17. Kanbay M, Gür G, Arslan H, Yilmaz U, Boyacioglu S: The relationship of ABO blood group, age, gender, smoking, and Helicobacter pylori infection. Dig Dis Sci 2005, 50(7):1214-1217.

18. Jaff MS: Relation between ABO blood groups and Helicobacter pylori infection in symptomatic patients. Clin Exp Gastroenterol 2011, 4:221-226.

19. Lopes M, Alves S, Barreira R, Ferreira P, Figueiredo J, Osorio N, Caseiro A, Valado A, Gabriel A, Mendes F: Helicobacter pylori infection and ABO and Lewis blood groups. Lab Med 2013, 40(2):35-39.

20. Tadege T, Mengistu Y, Desta T, Asrat D: Seroprevalence of Helicobacter pylori infection in and its relationship with ABO blood groups. Ethiop J Health Dev 2005, 19(1):55-60.

21. Seyda T, Derya C, Füsun A, Meliha K: The relationship of Helicobacter pylori positivity with age, sex, and $\mathrm{ABO} /$ Rhesus blood groups in patients with gastrointestinal complaints in Turkey. Helicobacter 2007, 12(3):244-250.

22. Niv Y, Fraser G, Delpre G, Neeman A, Leiser A, Samra Z, Scapa E, Gilon E, Bar-Shany S: Helicobacter pylori infection and blood groups. Am J Gastroenterol 1996, 91:101-104.

23. Tadesse T, Mulugeta G, Shimelis T: Evaluation of SD BIOLINE rapid antibody test for diagnosis of Helicobacter pylori infection. J Med Lab Diagn 2013, 4(5):62-66.

24. Desta K, Asrat D, Derbie F: Seroprevalence of Helicobactor pylori infection among health blood donors in Addis Ababa, Ethiopia. Can I Gastroenterol 2007, 21:501-506.

25. Tsega E, Gebre W, Hathaway A, Kassa E: Helicobacter pylori in Ethiopian patients with dyspepsia. Ethiop Med J 1996, 2:145-152.

26. Kassa $\mathrm{E}$, Tsega $\mathrm{E}$, Gebre W: Comparison of diagnostic methods for detection of Helicobacter pylori. East Afr Med J 1996, 73:239-241.

27. Mathewos B, Moges B, Dagnew M: Seroprevalence and trend of Helicobacter pylori infection in Gondar University Hospital among dyspeptic patients, Gondar, northwest Ethiopia. BMC Res Notes 2013, 6:346.

28. Jafarzadeh A, Ahmedi-Kahanali J, Bahrami M, Taghipour Z: Seroprevalence of anti-Helicobacter pylori and anti-CagA antibodies among healthy children according to age, sex, ABO blood groups and Rh status in southeast of Iran. Turk J Gastroenterol 2007, 18(3):165-171.

29. Aryana K, Keramati MR, Zakavi SR, Sadeghian MH, Akbari H: Association of Helicobacter pylori infection with the Lewis and $\mathrm{ABO}$ blood groups in dyspeptic patients. Niger Med J 2013, 54:196-199.
30. Valliani A, Khan F, Chagani B, KhuwajaA K, Majid S, Hashmi S, Nanji K, Valliani S: Factors Associated with Helicobacter pylori infection, results from a developing country-Pakistan. Asian Pac J Canc Prev 2013, 14(1):53-56.

31. Broutet N, Sarasqueta AM, Sakarovitch C, Cantet F, Lethuaire D, Megraud F: Helicobacter pylori infection in patients consulting gastroenterologists in France: prevalence is linked to gender and region of residence. Eur J Gastroenterol Hepatol 2001, 13:677-684.

doi:10.1186/1756-0500-7-834

Cite this article as: Tadesse et al:: Seroprevalence of Helicobacter pylori infection and its related risk factors in symptomatic patients in southern Ethiopia. BMC Research Notes 2014 7:834.

\section{Submit your next manuscript to BioMed Central and take full advantage of:}

- Convenient online submission

- Thorough peer review

- No space constraints or color figure charges

- Immediate publication on acceptance

- Inclusion in PubMed, CAS, Scopus and Google Scholar

- Research which is freely available for redistribution

Submit your manuscript at www.biomedcentral.com/submit
C Biomed Central 